\title{
An Interplay of Oral and Written Communication and Performance of Undergraduates
}

Farah Deeba ${ }^{1}$, Muhammad Abiodullah ${ }^{2}$, Khalid Khurshid ${ }^{3}$

\begin{abstract}

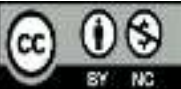

Students' proper use of oral and written communication plays a vital role in elevating their performance at the higher education level. Therefore, this study was conducted to explore the interplay of these communication types with the performance of undergraduates. A five point Likert-type scale was administered on a sample of 540 Bahauddin Zakariya University, Multan enrolled in the BS program of three faculties (Social Sciences, Sciences, and Languages). Students' performance was assessed by their CGPA (Cumulative Grade Point Average) in previous semesters, further correlated with their communication skills. All respondents were selected from three semesters of the BS program from twelve departments whose total population was two thousand two hundred and twentynine. For the analysis of data, mean and standard deviation were used as descriptive statistics, while Pearson's Product Moment and one-way ANOVA were used as inferential statistics. After analysis, a statistically significant positive correlation between CGPA and written communication was revealed However, no statistically significant interplay was found between CGPA and oral communication. It was found that there is no statistically significant difference in mean scores of students of different faculties on oral and written communication.
\end{abstract}

Keywords: Interplay, Oral, Written Communication, Performance, Undergraduates

\section{Introduction}

Communication is the progression of a message, through which verbal or non-verbal messages, or both, are transferred by the sender to the receiver. It refers to the tact and ability to convey commendably and competently using the following four language parameters: listening, speaking, reading, and writing. Our ability to communicate is evaluated on the effective use of these parameters. We can communicate in written and oral form. When we communicate orally, it

\footnotetext{
${ }^{1}$ Assistant Professor, Department of Education, Bahauddin Zakariya University, Multan Email: farahgillani@,bzu.edu.pk

${ }^{2}$ Associate Professor, Institute of Education and Research, University of Punjab, Lahore Email: abiodullah.ier@pu.edu.pk

${ }^{3}$ Professor/Chairman, Department of Education, Bahauddin Zakariya University, Multan. Email: khalidkhurshid@,bzu.edu.pk
} 
contains speaking and listening. The sender conveys the message orally, and the receiver listens along with oral feedback. Writing and reading are part of written communication wherein the sender communicates using the written format as an email, letter, memo, text, or fax. The receiver sends a response after having $\mathrm{read} /$ interpreted the message while involving skills of writing and reading (Srivastava, 2018).

In the present era, in the educational context, the focus of teaching and learning is changed for students as it demands them to be active communicator from passive one. Effective communication by the students is regarded as a vital component for academic accomplishment. Effective use of communication skills helps students to build trust and success in their academic life. Therefore, poor communication during studies may affect students' academic performance (Khalidzuoud \& Rawyaalshboul, 2018) because communication skills help them to listen and understand teachers' points of view in the class in a more advanced manner. After listening and understanding what teachers are speaking, students can ask better questions with confidence. It will help them gain more knowledge and interpret the teachers' communicated words more precisely. Clear communication, better use of vocabulary while interacting with interviewers and confident physical expressions help students build a career in their respective fields. In the future, students will have to communicate with clients by text, audio, and video conferencing in their workplace. If they are not effective in emails, tweets, and social engagement, it will negatively impact their career progress. Therefore, it is widely accepted that listening, writing and verbal communication play a vital role in students' personal and career development and even in culminating their performance during studies (Sharma, 2020).

Furthermore, higher education institutions globally are acknowledging the need to teach communication skills to students. Higher education is preparing graduates to fit them for various fields according to market needs. Therefore, it emphasizes improving students' academic progress and fostering 'life skills' in students like having good communication, which is required to compete in the global market arena. Moreover, now employers also place great value on the command over communication in choosing their future employees (Iksana et al., 2012). University students who are preparing themselves to join a career in the upcoming future should take the opportunity to be involved in all those activities that develop communication skills in them in a broader sense. Therefore, students need to put in the effort to develop their communication skills to succeed in their chosen profession (Ihmeideh et al., 2010).

Generally, we can communicate with each other in several ways, depending on the situation and need; however, it commonly involves oral and 
written skills (Iksana et a1., 2012). Mahmud (2014) indicates four types of communication: verbal, written, non-verbal, and mediated, but she also agrees that the two most essential areas are oral and written communication. Furthermore, in her view, "oral communication is denoted not only by the enunciation of words but also the engagement of graphic and non-verbal features to convey the message further conveniently" (Mahmud, 2014, p.129). The students' oral communication continuum contains debates, speeches, presentation skills, group discussions, class participation, interpersonal communication, role playing and public speaking. They play a significant role in exchanging ideas and comprehending informational content that ultimately enhances their selfexpression. When students informally converse with each other, they speak spontaneously. When they plan the content for any classroom presentations or group discussion, it paves the way for improved academic performance. A good array of oral communication works as a bonus for students. As a result, they acquire the right skills for giving shape to their ideas and articulate concepts, and initiatives.

In Stockwell's (2017, p. 36) view, "Written communication is the development and expression of ideas in writing. Written communication involves learning to work in many genres and styles. It can involve working with many different writing technologies and mixing texts, data, and images". Mahmud (2014, p.127) further explains in this manner that "Written communication reports on what writing is, how writing gets done, and what writing does in the world, consistently providing readers with new research findings, new theoretical concepts and new ways of understanding how writing is practiced in schools, workplaces, and communities."

Nevertheless, students' performance at higher education level during exams is mainly assessed based on their command over their writing skills. Therefore, it is strongly suggested by Asemanyi $(2015, \mathrm{p} .1)$ that students should improve their skills of 'note-taking and note making' from lectures, textbooks while outlining the material. They should be able to 'skim, scan and summarize' the given material in their own words while enabling themselves for 'conventions of usage' for spellings, Grammar, punctuation, and documentation. Lastly, they should emphasize sentence and clause patterns and use proper paragraphing for appealing an introduction, body and conclusion to any piece of writing.

According to Waring (2007) writing is the prime component of written communication because it has always been used for the erudition of any material due to its stimulating property, which primarily stimulates thinking. Written communication is further classified into two types: formal and informal. Each type fulfills particular purposes in the academic context. Formal writing is 
conditioned with 'pre-writing, drafting, revision, editing and publishing to present the writer's thoughts in a well-written manner. However, Waring (2007, p.13) further differentiates the value of informal writing as "a way of free expression in which student writes freely without worrying about mistakes while using it in note-taking, listing, diagrams, summaries, and journaling. It is considered as a learning tool rather used as assessment".

Students' overall excellence in their studies is considered their academic performance, which is communicated by using the Cumulative Grade Point Average (CGPA) under the semester system in universities of Pakistan. For summative assessment, students are assessed based on their performance in midterm and final exams, which are based on written paper, along with their sessional marks primarily composed of presentations, viva, and written assignments. This break up of exams demands students to focus on writing and verbal skills to achieve high grades and CGPA (Mahmud, 2014).

In universities of Pakistan, students also have to study while using their oral and written communication skills to perform better and improve their performance. It is generally considered that they should be communicative, and for this purpose, various activities are arranged for them like presentations, focused group discussions, seminars, written assignments to improve their academic writing. Such activities and practices boost their communication skills. It is hoped that that these practices may directly help them get better jobs because all jobs demand excellence in both oral and communication skills. However, the study was conducted to determine the interplay of students' oral and written communication skills with their performance at the university level because students' performance is mainly dependent on students' command over their academic writing skills and how they express themselves while using their oral skills. Various research studies have found that both communication skills have a profound effect on students' performance, such as Amadi and Paul (2017), Mahmud (2014), Ihmeidh etal. (2010), Yahaya and Ramli (2009) found solid and positive interplay in communication and performance of students. Cristobal and Lasaten (2018) also explored a significant correlation between academic performance and students' oral communication. It was evident from the results that both oral and written communication skills complement each other.

However, for effective written communication which may improve students' performance at higher education level, it is to be prioritized by the students to be proficient in systematic note taking from lectures, websites and books because lack of organized note taking cause forgetfulness of material. Teachers may help them in being competent for note taking. It includes understanding the material, quoting exact wordings of any author, paraphrasing, 
scanning, skimming, sequencing, summarizing and evaluation of one's own work while keeping in view grammar, spelling, punctuation and finally documenting the material. On the other hand, for the improvement of oral communication, students should participate in presentations of their assignment, be involved in other oral activities like welcoming an assignment based on viva or discussion to be proficient themselves orally. Such activities will enhance their academic performance as well. However, generally it is noticed that students do not consider the importance of communication skills that these skills will be beneficial for their academic performance and future careers. They overlook their mistakes in their write up and if they feel themselves inferior to talk fluently they have only solution for that they avoid oral exam based activities. Keeping in view this scenario in universities, researcher thought appropriate to conduct this research to explore students' oral and written communication skills while further correlating it with their academic achievement as well.

\subsection{Statement of the Problem}

Students' academic performance is prone to important aspects like family background, interest, study habits, motivation level, and communication skills. In this era, command over written and oral communication is vital for a student's prosperous future. In today's competitive world, the exchange of information complements quality learning. In sum, without communication, learning cannot flourish. However, in Pakistan, students of public universities mostly have the strong influence of their mother tongue in their communication as they come from lower and middle-economic status family backgrounds pass through public schools and colleges under an annual system. They lack command over academic writing and public speaking in the form of presentations and seminars. Therefore they are unable to perform well in job interviews when they pass out from university. If they successfully get a job, they cannot demonstrate the knowledge they have learned in university. This modern world of technology, electronic and print media demands well-communicated youth to compete in universities and workplaces in the future. This study was conducted to explore whether communication skills have an association with the students' performance or not. Command overwritten and oral communication skills need to be taken seriously to enrich students' academic experiences.

\subsection{Research Questions}

This study was conducted to reveal the answers to the following questions in the context of the sample studied.

1. Is there any interplay between students' oral and written communication and their performance in studies based on their CGPA? 
2. Is there any difference in communication skills and performance of male and female students?

3. Is there any interplay between students' oral, written communication and their academic performance based on their faculties and departments?

\subsection{Delimitation of the Study}

This study was delimited to male and female students of the BS program enrolled in three faculties (Language, Sciences and Social Sciences) of Bahauddin Zakariya University, Multan, studying in $2^{\text {nd }}, 5^{\text {th }}$ and $7^{\text {th }}$ semesters, respectively.

\section{Literature Review}

Communication has always been considered a key tool to negotiate well with one another and accomplish desired targets. Therefore, in an academic scenario, students always need to command their oral and written communication skills. It is always desirable for the students to obtain high CGPAs in their exams and further efficiently work as professionals. This dream can come true with their zeal for studies, a high level of motivation, interest, inclination towards studies, and high proficiency in oral and written communication (Srivastava, 2018). Khalidzuoud and Rawyaalshboul (2018) also agree that oral and written communication paves the way to success for university students, while poor communication is a barrier to their success. Furthermore, Mentoor (2015) opines that the students' academic performance is their excellence in accomplishing their given tasks in their academic environment. However, it is a demand of an everchanging and varied teaching and learning milieu to get students dexterous in the communication sphere, covering both oral and written skills, to improve their performance in the long run. For this purpose, Mentoor proposes three approaches, "text-based approach, communicative approach, and process approach" to be adopted by the teachers. The purpose of a text-based approach is to enable students to be habitual in focusing attention on the text. It allows them to redesign the given material by highlighting the major points and separating relevant and irrelevant. Only skilled, self-assured readers and writers can do this task. A strong communicative approach demands that we expose students to activities in which they may indulge themselves in communicating verbally with their peers for social interaction. In contrast, a process approach focuses them on interpreting written or oral texts, concentrating on the manifestation of their thoughts in an acceptable academic manner.

Mahmud (2014) considers oral channels as influential factors for students' academic excellence as poor communication would take them towards failure at their studies, poor grades, and even to drop out. Furthermore, orally adept learners find themselves confident while interacting with their peers. 
Ultimately, these self-confident students set standards for themselves to meet expectations while interacting verbally. Mahmud correlates academic performance significantly with oral communication and deduces that good oral communication stimulates students to perform better academically. Iyamu (2005) also found a significant positive correlation between oral communication and students' performance. It can be concluded that oral communication is a prerequisite for enhanced learning. However, it requires an interactive social climate in classrooms created by the teacher to improve academic performance. To value this, teachers should offer ample oral assignments like presentations, role-playing, and pair sharing.

The value of written communication and oral communication for university students is undeniable to foster their cognitive and communicative abilities. In Waring's $(2007$, p.17) view, "the purpose of writing is to explore, communicate and record ideas." However, students perceive writing as an uphill task because they lack an appealing writing up, which is needed in their research work, written assignments, essay and letter writing. Kim et al. (2021) support the promotion of writing skills in students as, from their point of view, the end product of writing is the emergence of higher-order thinking skills in students, which revolve around three cognitive processes, "analysis, evaluation and creativity" (p.21). In universities, students always need these higher-order thinking skills to behave and work as capable students and perform further as competent professionals as graduates. Moreover, Kim (2021) and associates found a positive correlation between academic performance and written communication. They propose that writing should be treated as a "learning tool" by students and teachers to acquire knowledge in a more meaningful manner.

Tok and Kandemir (2015) also found through their experimental study that when students were exposed to such creative writing exercises, they performed well in written exams. In this way, they improved their written performance. Tok and Kandemir propose and stress the need for teachers to include creative writing activities for students. They emphasize that fostering written communication will mean that writing will always be valued as much as other communication skills. Komba and his associates (2012) also exposed a significant relationship between students' written communication and academic performance. To expand oral and written communication skills in undergraduates, which may ultimately uplift their performance in studies in university, both oral and written communication in classrooms should increase students' understanding, learning, and performance. In this connection, Waring (2007, p.12) suggests, "Students should be taught a variety of ways to implement writing to increase learning in all content areas. Writing strategies such as 
underlining and note-taking should be used as ways to highlight and organize important points. Regardless of the writing length, students should be instructed on producing the writing, and techniques should be modeled accordingly".

Srivastava (2018) suggests that reflective learning/peer response and student feedback be introduced into classrooms in the same context. It was further postulated that Reflective Learning promotes critical reflection to facilitate transformative learning because reflection can transform traditional learning into a thought-provoking and conscious experience for students.

\subsection{Research Design}

\section{Research Methodology}

This study adopted a correlational design because the researcher wanted to analyze the interplay of two independent variables, oral and written communication, on one dependent variable, the students' performance. Mukaka (2012) justifies that correlational design assists the researcher in finding how independent and dependent variables closely co-variate from -1 to +1 . It also calculates the relationship of variables in the form of their strength and direction.

\subsection{Population and Sample}

There are a total of seven faculties in BZU, out of which three faculties, Social Sciences (14 departments), Natural Sciences (12 departments) and Languages (6 departments), were selected as sample.

For the sampling of departments keeping in view the time constraints and limited financial resources of the researcher, five departments from the faculty of Sciences, five from the faculty of Social Sciences and two departments from the faculty of Languages (English and Urdu) were selected for this study while adopting stratified sampling.

The total strength of students was 2229. For the sampling of students, a total of 15 students were taken from each department's semester using convenience sampling. In this way, a total of 45 students from each department were taken as a sample, 15 students from each semester $\left(2^{\text {nd }}, 5^{\text {th }}\right.$, and $\left.7^{\text {th }}\right)$. Therefore, the total sample of this study was 540, including both male and female students, in which total females were 279, and total males were 261 . 
Table 3.1

Demographic Characteristic of the Respondents $(N=540)$

\begin{tabular}{|c|c|c|}
\hline Variables & $\mathrm{N}$ & $\%$ \\
\hline \multicolumn{3}{|l|}{ Faculty } \\
\hline Social sciences & 225 & 41.7 \\
\hline Sciences & 225 & 41.7 \\
\hline Language & 90 & 16.7 \\
\hline \multicolumn{3}{|l|}{ Departments } \\
\hline Education & 45 & 8.3 \\
\hline Psychology & 45 & 8.3 \\
\hline Sociology & 45 & 8.3 \\
\hline International & 45 & 8.3 \\
\hline \multicolumn{3}{|l|}{ Relations } \\
\hline Pakistan Studies & 45 & 8.3 \\
\hline Physics & 45 & 8.3 \\
\hline Mathematics & 45 & 8.3 \\
\hline Zoology & 45 & 8.3 \\
\hline Statistics & 45 & 8.3 \\
\hline Telecommunication & 45 & 8.3 \\
\hline Urdu & 45 & 8.3 \\
\hline English & 45 & 8.3 \\
\hline \multicolumn{3}{|l|}{ Gender } \\
\hline Male & 261 & 48.3 \\
\hline Female & 279 & 51.7 \\
\hline \multicolumn{3}{|l|}{ Semester } \\
\hline $2^{\text {nd }}$ & 180 & 33.3 \\
\hline $5^{\text {th }}$ & 180 & 33.3 \\
\hline $7^{\text {th }}$ & 180 & 33.3 \\
\hline \multicolumn{3}{|l|}{ Grades } \\
\hline $\mathrm{A}+$ & 145 & 26.9 \\
\hline A & 220 & 40.7 \\
\hline $\mathrm{B}+$ & 111 & 20.6 \\
\hline B & 47 & 8.7 \\
\hline $\mathrm{C}+$ & 17 & 3.1 \\
\hline Min. CGPA =2.32, Max CGPA =4.00, & & $M \pm S D$ of $C G P A=3.44 \pm 0.35$ \\
\hline
\end{tabular}

Eighty-three percent of participants belong to social sciences and sciences, and $16.7 \%$ belong to language faculty. Sixty-seven percent of students were $\mathrm{A}$ and $\mathrm{A}+$ grade achievers, and the remaining were $\mathrm{B}$ and $\mathrm{C}$ grade achievers. 


\subsection{Instrumentation}

Two tools were adopted to correlate students' oral and written communication skills with their achievement: students' communication scale for measuring communication skills and students' CGPA in their previous semester.

To find out students' communication skills, PRCA (Personal Report of Communication Apprehension) developed by McCroskey (1984) for oral communication, and Hassel et al.'s (2000) version of WCA (Written Communication Apprehension) used by Gardner et al. (2005) in their study was adopted as a model instrument. However, these were further modified keeping in view the core objectives of the study. In the scales mentioned above, there were 24 items in each scale separately. However, for this research, both scales were adapted in terms of the total number of items which were reduced to a total of 24 items, 12 items for oral and 12 items for written communication which were merged in the same scale relatively different scale for oral and written communication having seven positive items and 5 negatives for oral communication, 6 positive items, and 6 negative items for written communication without any breakup of both types of communication. Respondents had to give their response on 5 points Likert-type scale ranging from 1-5. Respondents were asked to mention their CGPA while filling the scale, which was further verified from the gazette of their respective departments. For the validation of tool, expert opinion was got and in the light of those opinions the instrument was found valid because it measured what it was supposed to measure.

\section{Data Analysis and Interpretation}

For the analysis of the description and interaction of variables, the Mean, Standard deviation, Pearson's Product Moment for correlation of variables and one-way ANOVA were calculated for comparison.

Table 4.1

Correlation between CGPA, Written and Oral Communication for the total dataset

\begin{tabular}{lcccc}
\hline Variables & 1 & 2 & 3 & 4 \\
\hline 1. CGPA & - & & & \\
2. Written Communication & $.146^{* *}$ & - & & \\
3. Oral Communication & .002 & $.332^{* *}$ & - & \\
4. Both Communications & .082 & $.774^{* *}$ & $.854^{* *}$ & - \\
\hline
\end{tabular}

Results of Table 4.1 show a statistically significant positive correlation between CGPA and written communication $(\mathrm{r}=.146, \mathrm{p}<.05)$. It is concluded that this correlation leads to the conclusion that good written communication of students supported their attainment of high CGPA scores. But there was no 
statistically significant correlation between CGPA and oral communication. There was no statistically significant correlation between CGPA and both communications.

Table 4.2

Pearson's correlation coefficient between oral and written communication skills and students' performance among various departments

\begin{tabular}{llll}
\hline & & & Communication \\
\cline { 3 - 4 } Departments & & Oral &. Written \\
\hline Education & CGPA & .103 & .146 \\
Psychology & CGPA & $-.298^{*}$ & $-.310^{*}$ \\
Sociology & CGPA & -.209 & .057 \\
International Relations & CGPA & -.059 & .223 \\
Pakistan Studies & CGPA & $.310^{*}$ & $.303^{*}$ \\
Physics & CGPA & -.025 & .160 \\
Mathematics & CGPA & .157 & .126 \\
Zoology & CGPA & -.159 & -.125 \\
Statistics & CGPA & .020 & .064 \\
Telecommunication & CGPA & .165 & $.308^{*}$ \\
Urdu & CGPA & $.329^{*}$ & .126 \\
English & CGPA & -.019 & $.425^{* *}$ \\
\hline
\end{tabular}

The results of the Pearson's coefficient of correlation in Table 4.2 exhibit that there was a significant negative correlation between CGPA and oral $(\mathrm{r}=$ $.298, \mathrm{p}<.05)$ and written $(\mathrm{r}=-.310, \mathrm{p}<.05)$ communication of Psychology students. There was a significant positive correlation between students' performance and oral $(\mathrm{r}=.310, \mathrm{p}<.05)$ and written $(\mathrm{r}=.303, \mathrm{p}<.05)$ communication of students of Pakistan Studies. There was a significant positive correlation between CGPA and written communication $(r=.308, \mathrm{p}<.05)$ among telecommunication students. There was a significant positive correlation between CGPA and Urdu students' oral communication $(\mathrm{r}=.329, \mathrm{p}<.05)$. There was a significant positive correlation between CGPA and English students' written communication $(\mathrm{r}=.425, \mathrm{p}<.05)$.

There was no significant correlation between CGPA and oral and written communication ( $p>$.05) of Education, Sociology, International Relations, Physics, Mathematics, Zoology, and Statistics students. 
Table 4.3

Pearson' correlation coefficient between oral and written communication skills and CGPA among various faculties

\begin{tabular}{llll}
\hline & & \multicolumn{2}{c}{ Communication } \\
\cline { 3 - 4 } Faculties & & Oral &. Written \\
\hline Social sciences & CGPA & -.120 & .080 \\
Sciences & CGPA & .108 & .163 \\
Language & CGPA & .124 & $.296^{*}$ \\
\hline
\end{tabular}

Table 4.3 shows a statistically significant positive correlation between CGPA and written communication of language students $(\mathrm{r}=.296, \mathrm{p}<.05)$. It is concluded that good written communication of languages students appears to support attaining high CGPA scores. However, there was no statistically significant correlation between CGPA and oral and written communication of students belonging to Social sciences and Sciences faculties.

Table 4.4

Means and SD of scores of Oral, Written Communication skills of Male and Female Students

\begin{tabular}{|c|c|c|c|c|c|c|}
\hline \multirow[b]{2}{*}{ Communication } & \multicolumn{2}{|c|}{ Male } & \multicolumn{2}{|c|}{ Female } & \multicolumn{2}{|c|}{ Independent Samples t-test } \\
\hline & $\mathrm{M}$ & SD & $\mathrm{M}$ & SD & $\mathrm{t}$ & $\mathrm{p}$ \\
\hline Oral & 3.45 & 0.59 & 3.32 & 0.65 & 2.28 & $0.023^{*}$ \\
\hline Written & 3.36 & 0.52 & 3.42 & 0.51 & -1.27 & 0.205 \\
\hline Overall & 3.40 & 0.47 & 3.37 & 0.47 & 0.825 & 0.410 \\
\hline
\end{tabular}

$* \mathrm{p}<.05$

Table 4.4 indicates a statistically significant difference in mean scores of male and female students on Oral Communication $(\mathrm{p}<.05)$. The mean score of Male students $(M=3.45, S D=0.59)$ on oral communication was higher than the mean score of Female students $(M=3.32, S D=0.65)$. However, there was no significant difference in the mean score of male students and female students on written communication ( $\mathrm{p}>.05)$.

Table 4.5

Means and SD of Scores of Oral, Written Communication skills of Students belonging to different faculties

\begin{tabular}{|c|c|c|c|c|c|}
\hline \multirow[b]{2}{*}{ Communication } & \multirow{2}{*}{$\begin{array}{c}\text { Social Sciences } \\
\mathrm{M}(\mathrm{SD}\end{array}$} & \multirow{2}{*}{$\begin{array}{l}\text { Sciences } \\
\mathrm{M}(\mathrm{SD})\end{array}$} & \multirow{2}{*}{$\begin{array}{c}\text { Languages } \\
\mathrm{M}(\mathrm{SD})\end{array}$} & \multicolumn{2}{|c|}{ One-Way ANOVA } \\
\hline & & & & $\mathrm{F}$ & $\mathrm{P}$ \\
\hline Oral & $3.40(0.66)$ & $3.36(0.57)$ & $3.41(0.66)$ & 0.325 & 0.723 \\
\hline Written & $3.42(0.48)$ & $3.35(0.5$ & $3.42(0.5$ & 1.108 & 0.331 \\
\hline Overall & $3.41(0.47)$ & $3.36(0.44)$ & $3.42(0.51)$ & 0.920 & 0.399 \\
\hline
\end{tabular}


Table 4.5 shows no statistically significant difference in mean scores of students belonging to different faculties on Oral and Written Communication $(\mathrm{p}>.05)$.

Table 4.6

Means and S.D.s of Scores of Oral, Written Communication skills of Students belonging to different departments

\begin{tabular}{lccc}
\hline & \multicolumn{3}{c}{ Communication } \\
\cline { 2 - 4 } Departments & $\mathrm{M}(\mathrm{SD})$ & $\mathrm{Written}$ & Overall \\
Education & $3.33(0.51)$ & $3.41(0.44)$ & $3.37(0.40)$ \\
Psychology & $3.14(0.64)$ & $3.36(0.42)$ & $3.25(0.42)$ \\
Sociology & $3.68(0.91)$ & $3.46(0.52)$ & $3.57(0.58)$ \\
International & $3.44(0.65)$ & $3.41(0.58)$ & $3.43(0.52)$ \\
Relations & & & \\
Pakistan Studies & $3.39(0.43)$ & $3.44(0.44)$ & $3.41(0.35)$ \\
Physics & $3.35(0.56)$ & $3.30(0.52)$ & $3.33(0.44)$ \\
Mathematics & $3.38(0.56)$ & $3.22(0.53)$ & $3.30(0.46)$ \\
Zoology & $3.58(0.66)$ & $3.61(0.51)$ & $3.59(0.47)$ \\
Statistics & $3.20(0.46)$ & $3.33(0.48)$ & $3.26(0.33)$ \\
Telecommunication & $3.28(0.54)$ & $3.31(0.50)$ & $3.30(0.43)$ \\
Urdu & $3.47(0.59)$ & $3.37(0.52)$ & $3.42(0.49)$ \\
English & $3.35(0.73)$ & $3.48(0.62)$ & $3.41(0.54)$ \\
$F$ & 2.702 & 1.751 & 2.631 \\
$p$ & .002 & .060 & .003 \\
\hline \multicolumn{4}{c}{ Results of Table 4.6 demonstrate a statistically significant difference in } \\
mean scores of students belonging to different departments on Oral \\
Communication (p<.01). The highest mean score (M=3.68, SD=0.91) of \\
Sociology students was highest among students belonging to other departments, \\
and mean scores (M=3.14, SD=0.64) of Psychology students were lowest.
\end{tabular}




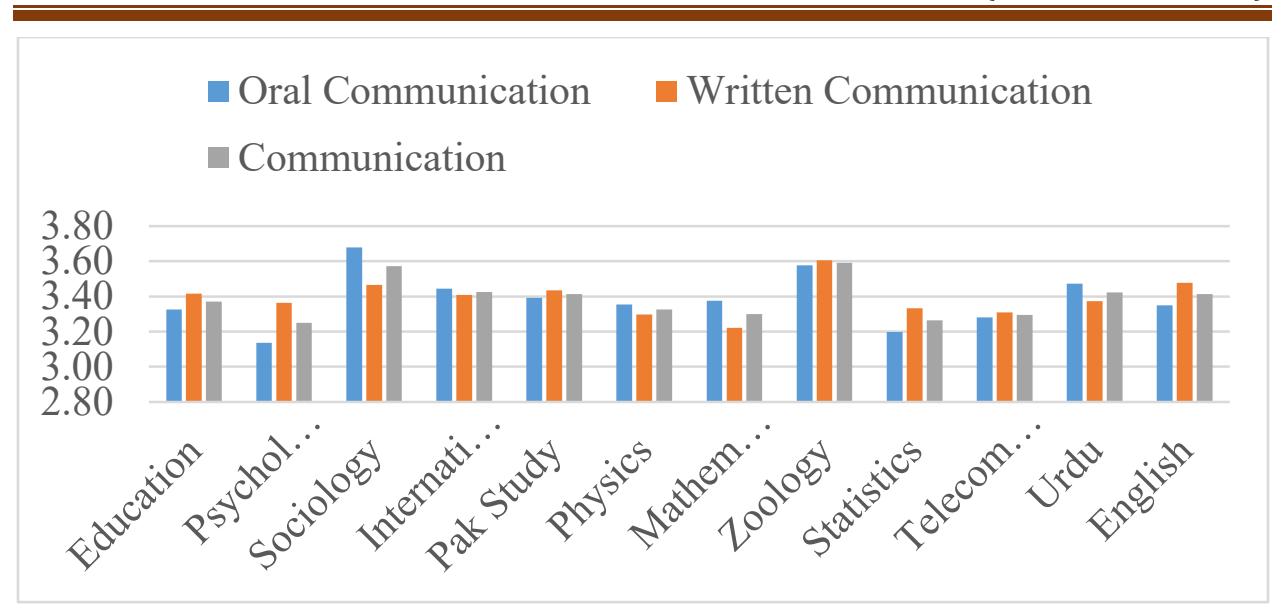

Figure 1. Comparison of students belonging to different departments on communication

\section{Discussion and Conclusion}

This study was conducted to reveal the interplay of students' written and oral communication use with their performance in studies who were enrolled in the BS program in three faculties (Social Sciences, Natural Sciences, and Languages) of Bahauddin Zakariya University, Multan. Analysis of the data collected from students' self-reported survey exposed a positive and significant relationship between written communication skills and CGPA of students, rather than overall communication skills, which showed no significant relationship with their CGPA. Even students of the Faculty of Languages showed a positive interplay between their reported written communication and achievement. It can be concluded that students feeling that they have command over their write-ups perform better in their studies. This can be because the requirements of our examination system promote and emphasize writing abilities more than oral skills. As students mostly have to take written exams and assignments to pass the exam, they ignore their oral skills and focus on writing skills. This result is quite similar to the study results by Mentoor (2015), who also exposed that there was no significant relationship between communication skills and academic performance. However, she believes that there was a significant association between achievement and oral communication based on the evidence she collected.

Similarly, Gardner et al. (2005) showed gender-based differences in oral communication. According to the results of their study, females were significantly higher in oral communication. In their view, female students exhibit better communication skills as compared to male counterparts. The study also 
found a statistically significant difference for males and females on oral communication. However, male students were found to have command over oral skills far better than females.

Contrary to this, no significant difference in oral communication between male and female undergraduate students by Dar and Khan (2014). For written communication, Gardner et al. (2005) also did not find any significant gender difference. These results align with this study as no significant difference was found between males and females in written communication. Even students of all three faculties had no significant difference in oral and written communication. Furthermore, Gardner et al. (2005) found a significant correlation for written communication and a negative correlation for oral communication, like Mahmud (2014), who also found that good academic performance did not correlate with oral communication and other factors were affecting performance. The study result by Mahmud is in line with the results of the study as no significant relationship was found in oral communication and the implementation of students.

It can be concluded that students who have not yet developed their communication skills may encounter difficulties in learning, which hinders their performance. Communication skills, whether oral, written or interpersonal, are crucial for their future careers in higher education. In classrooms where teachers design such activities that foster communication skills in students like journal writing, written assignments, role-playing, presentations, and viva voce exams, it helps students to have command over both types of communication. In this way, higher education is a platform for students to use their potential. Students have potential; however, it is the responsibility of teachers to evoke that potential to prepare them for future market needs. In this way, teachers should provide extensive feedback on their written and oral assignments while indicating strong and weak points that hinder achieving high CGPAs. Once students know their weaknesses, it aids them to improve those points in their assessments to improve their performance.

\section{Recommendations}

1. Students should be engaged in written activities that link to real-life tasks expected of them to elevate their performance in such tasks, such as writing research papers for journals for improved academic writing, letter writing, written assignments, filling up proforma, and essay writing. In this way, they can be well trained to transform their ideas in their wordings rather than depending on 'bookish' language.

2. Command over communication skills should be emphasized in curricular activities by all faculties rather than only the faculty of languages. 
3. Practical experiences should be provided to students to be prepared for interviews and oral-type exams.

\section{References}

Amadi, G. \& Paul, A. K. (2017). Influence of student-teacher communication on students' academic achievement for effective teaching and learning. American Journal of Educational Research, 5(10), 11021107.doi: 10.12691/education-5-10-12

Asemanyi, A. A. (2015). An assessment of students' performance in communication skills: A case study of the University of Education Winneba. Journal of Education and Practice, 6(35), 1-7.

Cristobal, A. J. \& Lasaten, C. R. (2018). Oral communication apprehension and academic performance of grade 7 students. Asia Pacific Journal of Multidisciplinary Research, 6(3), 5-16.

Dar, M. F. \& Khan, I. (2014). Oral communication apprehension among undergraduate engineering students in Pakistan. Journal of Education and Social Sciences, 2(2), 144-153.

Gardner, T. C., Milne, J. M., Stringer, P. C. \& Whiting, H. R. (2005). Oral and written communication apprehension in accounting students: Curriculum impacts and impacts on academic performance. Accounting Education, 14(3), 313-336.

Hassall, T., Joyce, J., Ottewill, R., Arquero, J., \& Donoso, J. (2000). Communication apprehension in UK and Spanish business and accounting students. Education+Training, 42(2), 93-100.

Iyamu, E. O. S. (2005). Relationship between verbal ability and students' achievement in secondary school social studies in Southern Nigeria. Language in India, 5(3).

Ihmeideh, F.M., Al-Omari, A. A. \& Al-Dababneh, K. A. (2010). Attitude toward communication skills among student teachers in Jordanian public universities. Australian Journal of Teacher Education, 35(4), 1-11.

Iksana, H. Z., Zakariaa, E., Meeraha, T.S.M., Osman, K,, Lian, D. K. C., Mahmud, S.N.D. \& Krish, P. (2012). Communication skills among 
university students. Procedia-Social and Behavioral Sciences, 59, 71-76. doi: 10.1016/j.sbspro.2012.09.247

Khalidzuoud, V., \& Rawyaalshboul, S.A. (2018). The effects of communication skills in developing preparatory year students' performance. Proceedings of Academics World $82^{\text {nd }}$ International Conference, Langkawi, Malaysia, $18^{\text {th }}-19^{\text {th }}$ June 2018 Retrieved from www.worldresearchlibrary.org $>$ pdf.

Kim, S., Yang, W.J., Lim, J., Lee, S., Ihm, J. \& Park, J. (2021). The impact of writing on academic performance for medical students. BMC Medical Education. 21(61), 2-8.

Komba, S. C., Kafanabo, E. J., Njabili, A. F., \& Kira, E. S. (2012). Comparison between students' academic performance and their abilities in written English language skills: A Tanzanian perspective. International Journal of Development and Sustainability, 1(2), 305-325.

Mahmud, M. M. (2014).Communication aptitude and academic success. Procedia-Social and Behavioral Sciences, 134, 125-133. doi: 10.1016/j.sbspro.2014.04.230

McCroskey, J. C. (1984). The communication apprehension perspective. In JA Daly \& J.C. McCroskey (Eds), Avoiding Communication (pp. 13-38). Beverly Hills, California: Sage Publications.

Mentoor, M. Z. (2015). An analysis of relationship between communication skills, communication apprehension and academic achievement of secondary phase learners (Unpublished master's thesis). North-West University, Potchefstroom, South Africa.

Mukaka, M. M. (2012). A guide to appropriate use of correlation coefficient in medical research. Malawi Medical Journal, 24(3), 69-71.

Sharma, V. K. (2020).Importance of communication skills for students. Retrieved from https://www.klientsolutech.com

Srivastava, K. (2018). Self-assessment of communication skills by management students: an empirical study in Indian context. Journal of English Education, 6(2), 11-18. 
Stockwell, A. (2017). Assessing student performance in written communication: An evaluation of the University of Kentucky's quality enhancement plan. Retrieved from http://uknowledge.uky/mpampp_etds 286.

Tok, S. \& Kandemir, A. (2015). Effects of creative writing activities on students' achievement in writing, writing disposition and attitude to English. Procedia-Social and Behavioral Sciences, 174, 1635-1642.

Waring, J. W. (2007). The impact of writing on student achievement. (Unpublished master's thesis). Watson School of Education University of North Carolina Wilmington.

Yahaya, A. \& Ramli, J. (2009). The relationship between self-concept and communication skills towards academic achievement among secondary school students in Johor Bahru. International Journal of Psychological Studies, 1(2), 25-34.Retrieved from www.ccsenet.org/journal.html

\section{Citation of this Article:}

Deeba, F., Abiodullah, M., \& Khurshid, K. (2021). An Interplay of Oral and Written Communication and Performance of Undergraduates. International Journal of Innovation in Teaching and Learning (IJITL), 7(2), 52-69. 